\title{
Composition-tuned Pt-skinned PtNi bimetallic clusters as highly efficient methanol dehydrogenation catalysts
}

\author{
Ting-Wei Liao ${ }^{1,{ }^{*}, \neq, \dagger}$, Anupam Yadav ${ }^{1, \neq}$, Piero Ferrari ${ }^{1}$, Yubiao Niu ${ }^{2}$, Xian-Kui Wei3, Jerome \\ Vernieres², Kuo-Juei Hu', Marc Heggen³, Rafal E. Dunin-Borkowski³, Richard E. Palmer², Kari \\ Laasonen ${ }^{4}$, Didier Grandjean ${ }^{1, *}$, Ewald Janssens ${ }^{1}$, and Peter Lievens ${ }^{1,{ }^{*}}$ \\ ${ }^{1}$ Quantum Solid State Physics, Department of Physics and Astronomy, KU Leuven, Celestijnenlaan 20oD, box 2414, \\ BE-3001 Leuven, Belgium. \\ ${ }^{2}$ College of Engineering, Swansea University, Bay Campus, Fabian Way, Swansea SA1 8EN, United Kingdom \\ 3 Ernst Ruska-Centre for Microscopy and Spectroscopy with Electrons and Peter Grünberg Institute \\ Forschungszentrum Jülich GmbH, Jülich 52428, Germany \\ ${ }_{4}$ Department of Chemistry and Materials Science, Aalto University, P.O. Box 1610o, FI-ooo76 Aalto, Finland.
}

\begin{abstract}
Platinum is the most active anode and cathode catalyst in next-generation fuel cells using methanol as liquid source of hydrogen. Its catalytic activity can be significantly improved by alloying with $3 \mathrm{~d}$ metals, although a precise tuning of its surface architecture is still required. Herein, we report the design of a highly active low temperature (below $o^{\circ} \mathrm{C}$ ) methanol dehydrogenation anode catalyst with reduced $\mathrm{CO}$ poisoning, based on ultra-low amount of precisely-defined $\mathrm{Pt}_{x} \mathrm{Ni}_{1-x}$ ( $x=\mathrm{o}$ to 1 ) bimetallic clusters (BCs) deposited on inert flat oxides by Cluster Beam Deposition (CBD). These BCs feature clear composition-dependent atomic arrangements and electronic structures stemming from their nucleation mechanism that are responsible for a volcano-type activity trend peaking at the $\mathrm{Pt}_{\mathrm{o} .7} \mathrm{Ni}_{\mathrm{o} .3}$ composition. Our calculations reveal that at this composition a cluster skin of Pt atoms with d-band centres downshifted by subsurface Ni atoms weakens the $\mathrm{CO}$ interaction that in turn triggers a significant increase in the methanol dehydrogenation activity.
\end{abstract}

\section{INTRODUCTION}

Low temperature proton exchange membrane fuel cells (PEMFC) and high temperature solid oxide fuel cells (SOFC) are emerging as efficient, low cost and environment-friendly solutions to harvest energy from diverse renewable sources, such as hydrogen, hydrocarbons, water, bio-fatty acids and bio-alcohols. Among these sources methanol is a promising energy raw material that can be either directly electro-oxidized to power direct methanol fuel cells (DMFCs) or easily thermo-catalytically decomposed or reformed in situ into a mixture of hydrogen and carbon monoxide that is then fed into a $\mathrm{H}_{2}$ fuel cell. Methanol-based fuel cells (MFCs) are more reliable than conventional $\mathrm{H}_{2}$ fuel cells, as liquid methanol is easier to store and transport than hydrogen gas. ${ }^{1,2}$ Although platinum is widely used as (electro)catalyst in the dehydrogenation of methanol $\left(\mathrm{CH}_{3} \mathrm{OH}\right), 3,4$ its performance is limited by its modest stability and

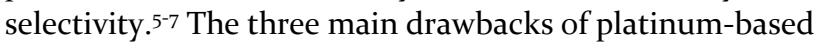
anode catalysts are their high cost as methanol bonds breaking requires large amounts of catalyst, ${ }^{8}$ their low selectivity to generate hydrogen as end product, and their low stability in presence of carbon monoxide, a by-product of methanol dissociation (i.e. the $\mathrm{CO}$ poisoning effect). 9 , 10 These crucial challenges require remediation in order to design future high performance fuel cell catalysts, for which fundamental understanding of the reaction kinetics at the atomic and molecular level are required. For this purpose, the reaction kinetics of model catalyst systems such as single Pt atoms, ${ }^{11} \mathrm{Pt}$ single crystals, ${ }^{12-14}$ oxidesupported Pt thin films,,$^{15}$ and Pt nanoparticles, ${ }^{6,7}$ have been investigated intensively.

Pt-alloy nanoparticles as fuel cell catalyst have shown higher activity and enhanced tolerance to $\mathrm{CO}$ poisoning. Several alloying materials such as $\mathrm{Sn}, \mathrm{Ru}, \mathrm{Mo}, \mathrm{Nb}, \mathrm{W}, \mathrm{Ag}$, and $\mathrm{Ni}$ have been investigated. ${ }^{16-19}$ Despite these efforts, the underlying mechanism for the alloy-induced activity and tolerance to the $\mathrm{CO}$ poisoning effect is still under debate. Some studies suggest that the co-adsorption of $\mathrm{CO}$ and $\mathrm{OH}$ groups is responsible for the induced tolerance, ${ }^{9}$ while others attribute the reduced $\mathrm{CO}$ poisoning mainly to alloying-induced alteration of the electronic structure of platinum..$^{20-22}$ Density functional theory calculations (DFT) ${ }^{13}, 3^{23-25}$ and experiments on few-atom clusters in the gas phase ${ }^{26,27}$ support the latter interpretation. This controversy is largely due to the lack of clear understanding of the effect of alloying on the catalyst activity. Depending on the particle size, shape, composition, spatial atomic arrangement and method of preparation, the activity can change drastically emphasizing the need for using well-characterized 
materials to identify the fundamental mechanisms at work. Pt-Ni bimetallic extended surfaces ${ }^{28-31}$, nanostructures ${ }^{32}$, nanoclusters and nanoparticles ${ }^{8}, 33,34$ that have shown enhanced activity for the oxygen reduction reaction (ORR) as methanol-tolerant cathode catalyst in fuel cell applications are also considered as promising anoderelated (electro)catalysts. In most cases the investigated Pt-Ni nanomaterials are produced with (electro) chemical methods that often have a limited control over the systems size and composition. Furthermore, the involvement of stabilizing chemicals in wet chemistry, such as ligand molecules, greatly alters the intrinsic properties of nanomaterials, making the understanding of their composition- and structure-dependent activity more complex. $35-40$

Depositing preformed Pt-based bimetallic clusters/nanoparticles, with precisely-defined size, composition and surface coverages ${ }^{41-44}$ on various oxide supports, using the Cluster Beam Deposition (CBD) technology could be one of the key solutions to design better fuel-cell catalysts. ${ }^{45}$ Clusters are particles typically composed of less than a thousand atoms and have dimensions smaller than a few nanometres. They have unique magnetic, ${ }^{46}$ optical, ${ }^{47}$ and catalytic ${ }^{44,48-50}$ properties, distinct from those of the bulk phase, which make them promising candidates for numerous applications. Their catalytic properties can be enhanced by a synergistic combination of different elements such as earth abundant $\mathrm{Ni}$ and precious $\mathrm{Pt}$ metal, which can at the same time improve significantly their activity, reduce the $\mathrm{CO}$ poisoning effect and the usage of abundance-critical platinum.

In this study, we use a laser ablation CBD source ${ }^{51,5^{2}}$ to produce and deposit $\mathrm{Pt}_{x} \mathrm{Ni}_{1-x}$ bimetallic clusters $(\mathrm{BCs})$ with an accurate control over their size and chemical composition. The BCs are deposited on two different supports, carbon TEM grids and native $\mathrm{SiO}_{2}$ surfaces, with different coverages ranging from $5 \%$ to $25 \%$ clusterprojected area coverage ( 1 to 5 atomic monolayers, ML). Using a combination of high angle annular dark field scanning transmission electron microscopy (HAADFSTEM), X-ray photoelectron spectroscopy (XPS) and temperature programmed desorption (TPD), the cluster composition-dependent atomic arrangement, activity and $\mathrm{CO}$ poisoning in the methanol decomposition reaction are demonstrated. DFT calculations on selected sizes of the most promising $\mathrm{Pt}_{\mathrm{0} .7} \mathrm{Ni}_{\mathrm{o} .3}$ composition $\left(\mathrm{Pt}_{353} \mathrm{Ni}_{106}\right.$ and $\mathrm{Pt}_{47} \mathrm{Ni}_{144}$ ) reveals that the increased catalytic activity and reduced $\mathrm{CO}$ poisoning effect by alloying $\mathrm{Pt}$ with $\mathrm{Ni}$ can be attributed to local d-band modifications of surface Pt-skin atoms by the presence of subsurface $\mathrm{Ni}$ atoms.

\section{COMPOSITION-TUNED SEGREGATED STRUCTURE IN PT ${ }_{X} \mathrm{NI}_{1-x}$ CLUSTERS}

The size distribution of $\mathrm{Pt}_{x} \mathrm{Ni}_{1-x}$ BCs with $x=0.9,0.7,0.5$, 0.3 and 0.1 was characterized by STEM. The distribution of the $\mathrm{BCs}$ average diameters in a sample of more than 300 clusters was measured for each $\mathrm{Pt}_{x} \mathrm{Ni}_{1-x}$ composition. A comparable size distribution (FWHMs of $1.4 \mathrm{~nm}$ ) with an average diameter around $2.0 \mathrm{~nm}$ was found for all the compositions (Figure $\mathrm{S} 1$ ). In order to characterize the atomic arrangement in $\mathrm{Pt}_{x} \mathrm{Ni}_{1-x}$ BCs, STEM images with high resolution were collected for all compositions. Given the large atomic number difference between $\mathrm{Pt}(78)$ and $\mathrm{Ni}$ (28), the atomic arrangement of these two elements within the $\mathrm{BCs}$ can be revealed with good contrast by their HAADF intensity profile.43, 53 If phase segregation occurs, the brighter and darker parts of the BCs can be assigned to Pt-rich and Ni-rich areas, respectively. Error! Reference source not found. presents selected STEM images of $\mathrm{Pt}_{x} \mathrm{Ni}_{1-x} \mathrm{BCs}$ along with their normalised quantitative radial intensity profile integrated over the polar coordinates. Detailed inspection of the STEM images indicates that, except for the $\mathrm{Pt}_{0.5} \mathrm{Ni}_{0.5}$ composition that is mostly alloyed, a composition-dependent phase segregation is prominent in all $\mathrm{BCs}$, where the minority and majority element prefers to concentrate in the core and shell of the $\mathrm{BCs}$, respectively.

This composition-tuned phase segregated atomic arrangement found in $\mathrm{Pt}-\mathrm{Ni}$ BCs suggests that their formation mechanism is governed by the preferential formation of binary few-atom clusters in the nucleation stage already proposed for $\mathrm{Au}_{x} \mathrm{Ag}_{1-x} \mathrm{BC}$ s produced with the same source. ${ }^{43}$ This is confirmed by computing and comparing the mixing energies defined as the binding energies of the small 4 -atom $\mathrm{Pt}_{3} \mathrm{Ni}_{1}, \mathrm{Pt}_{2} \mathrm{Ni}_{2}$ and $\mathrm{Pt}_{1} \mathrm{Ni}_{3} \mathrm{BC}$ and their monometallic counterparts $\mathrm{Pt}_{4}$ and $\mathrm{Ni}_{4}$, present in the gas-phase at the initial stages of the BCs nucleation and growth. As in the Au-Ag system, DFT calculations show that the formation of binary 4 -atom clusters is energetically more favourable than that of the monometallic ones (Figure S2). This strongly suggests that these stable binary few-atom Pt-Ni clusters will form and agglomerate before the monometallic ones, to form the BCs core enriched in the minority element. The remaining pure $\mathrm{Pt}$ or $\mathrm{Ni}$ few-atom clusters of the majority elements will then condense on the Pt-Ni nuclei to form the $\mathrm{BC}$ shell following the same composition-tuned segregation mechanism of a general character discussed earlier. ${ }^{43} \mathrm{~A}$

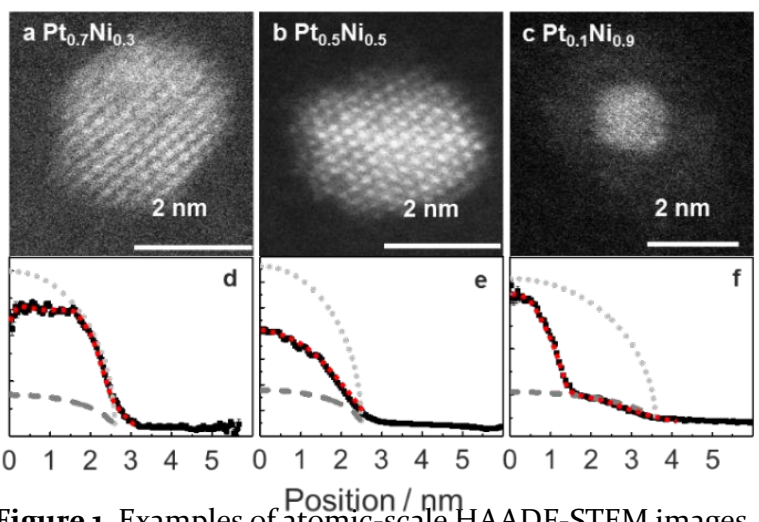

Figure 1. Examples of atomic-scale HAADF-STEM images of $\mathrm{Pt}_{\mathrm{x}} \mathrm{Ni}_{1-\mathrm{x}}$ BCs: (a, d) $\mathrm{Pt}_{0.7} \mathrm{Ni}_{0.3}$; (b, e) $\mathrm{Pt}_{0.5} \mathrm{Ni}_{\text {o. }}$; (c, f) $\mathrm{Pt}_{\mathrm{o} .1} \mathrm{Ni}_{\text {o.9. }}$. The HAADF-STEM radial intensity profiles $(\mathrm{d}, \mathrm{e}$, f) are taken from the centre to the edge of the cluster and integrated from $\mathrm{o}^{\circ}$ to $360^{\circ}$. The red dotted lines correspond to simulations of cluster STEM intensity profiles with gradient composition evolution. The light grey dotted lines and dark grey dashed lines are simulated ACS Paragon Plus EnSTEMPhintensities for pure Pt clusters and pure Ni clusters, respectively. 
detailed comparison of the preparation and structure of $\mathrm{Au}-\mathrm{Ag}$ and Pt-Ni systems is presented in Figure $\mathrm{S}_{3}$.
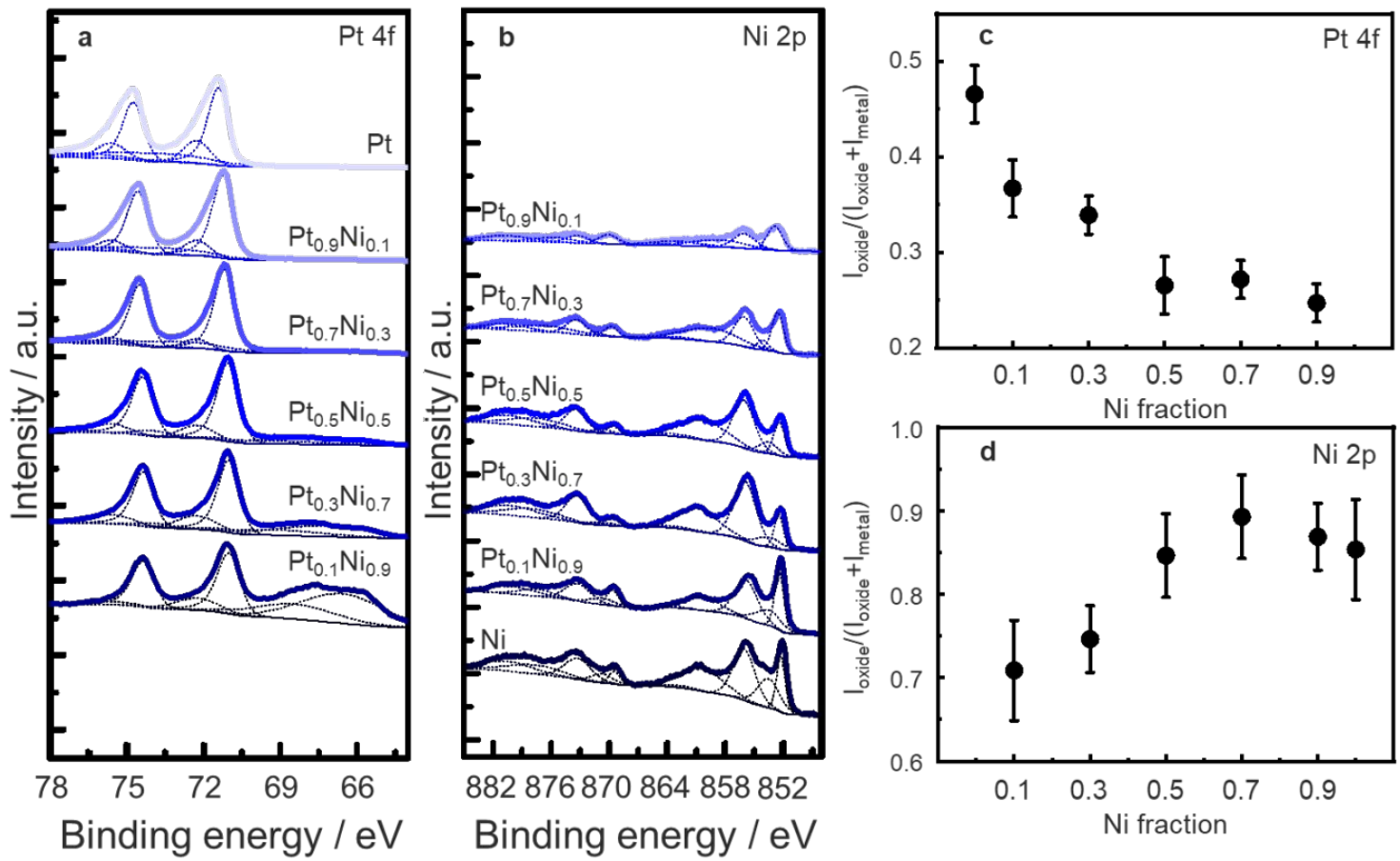

Figure 2. Pt $4 \mathrm{f}(\mathrm{a})$ and $\mathrm{Ni}$ 2p (b) XPS spectra of the $\mathrm{Pt}_{x} \mathrm{Ni}_{1-x} \mathrm{BCs}_{\text {on }} \mathrm{SiO}_{2}$ wafers from $x=0.9$ to o.1 as well as pure Pt and $\mathrm{Ni}$ clusters. The Pt $4 \mathrm{f}$ peaks of $\mathrm{Pt} 4 \mathrm{f}_{7 / 2}$ and $\mathrm{Pt} 4 \mathrm{f}_{5 / 2}$ are deconvoluted into $\mathrm{Pt}$ metal phase $(71.1 \mathrm{eV}$ and $74.4 \mathrm{eV})$ and Pt oxide phases $(72.3 \mathrm{eV}, 75.7$ $\mathrm{eV}, 73.9 \mathrm{eV}$ and $77.3 \mathrm{eV}$ ); the Pt $4 \mathrm{f} \mathrm{XPS}$ intensity ratio of the oxide phase is summarized in (c). The $\mathrm{Ni} 2 \mathrm{p}$ peaks of $\mathrm{Ni} 2 \mathrm{p} 3 / 2$ and $\mathrm{Ni}$ $2 \mathrm{pl} / 2$ are deconvoluted into a Ni metal phase $(852.5 \mathrm{eV}$ and $869.6 \mathrm{eV})$ and $\mathrm{Ni}$ hydroxide/oxide phases $(853.2 \mathrm{eV}, 870.7 \mathrm{eV}, 855.9$ $\mathrm{eV}, 873.4 \mathrm{eV}, 860.4 \mathrm{eV}, 877.9 \mathrm{eV}$ ); the Ni 2p XPS intensity ratio of the oxide phase is summarized in (d).

The electronic structure and the nature of the phases occurring in the air exposed $\mathrm{Pt}_{x} \mathrm{Ni}_{1-x} / \mathrm{SiO}_{2}(x=0,0.1,0.3,0.5$, $0.7,0.9$ and 1) samples were complementarily investigated by XPS. The composition and amount of the oxidized components can be revealed by deconvoluting the Pt $4 \mathrm{f}$ and Ni 2p peaks. The best fits of the high-resolution XPS core-level spectra in the $\mathrm{Pt} 4 \mathrm{f}$ and $\mathrm{Ni} 2 \mathrm{p}$ energy region, as well as the summary plots of $\mathrm{Pt} 4 \mathrm{f}$ and $\mathrm{Ni}$ 2p peaks with the different phases are presented in Figure 2. It is found that $\mathrm{Pt}$ atoms within the BCs mainly remained metallic and that a large fraction of $\mathrm{Ni}$ atoms was oxidized into $\mathrm{Ni}$ hydroxide/oxide after the samples were exposed to air. Furthermore, a composition dependent oxidation rate is observed. Pt $4 \mathrm{f}$ peaks can be deconvoluted into three sets of Pt $4 f_{7 / 2}$ and $\mathrm{Pt} 4 \mathrm{f}_{5 / 2}$ peaks, corresponding to Pt metal (71.1 $\mathrm{eV}$ and $74.4 \mathrm{eV}$ ), $\mathrm{PtO}\left(72.3 \mathrm{eV}\right.$ and $75.7 \mathrm{eV}$ ) and $\mathrm{PtO}_{2}$ phases (73.9 eV and $77.3 \mathrm{eV}$ ). Additionally, a broad peak that appears between $66 \mathrm{eV}$ and $69 \mathrm{eV}$ when the $\mathrm{Ni}$ fraction is above 0.5 can be assigned to convoluted $\mathrm{Ni}$ 3p peaks. The intensity evolution of these $\mathrm{Ni} 3 \mathrm{P}$ peaks is fully consistent with the $\mathrm{BC}$ composition.

Pure platinum and Pt-rich clusters feature a larger fraction of platinum oxides than their Ni-rich bimetallic counterparts. Pt oxides consist mostly of $\mathrm{PtO}$ with an additional contribution of the higher oxidation phase $\mathrm{PtO}_{2}$ that is only present in the Pt rich BCs. In BCs with $\mathrm{Ni}$ fractions above 0.5 , the $\mathrm{Pt}$ oxidation rate drops significantly. This observation is consistent with the STEM observation that Pt atoms are predominantly present in the $\mathrm{BC}$ core. This suggests that their oxidation is prevented by the Ni atoms forming the $\mathrm{BC}$ outer shell. Similarly, the oxidation state of the $\mathrm{Ni}$ atoms also varies with the $\mathrm{BC}$ composition. The $\mathrm{Ni} 2 \mathrm{p}_{3 / 2}$ and $\mathrm{Ni} 2 \mathrm{p}_{1 / 2}$ peaks can be deconvoluted into $\mathrm{Ni}$ metal $(852.5 \mathrm{eV}$ and $869.6 \mathrm{eV}), \mathrm{NiO}$ $(853.2 \mathrm{eV}$ and $870.7 \mathrm{eV}), \mathrm{Ni}(\mathrm{OH})_{2}(855.9 \mathrm{eV}$ and $873.4 \mathrm{eV})$ and $\mathrm{NiOOH}$ phases $(860.4 \mathrm{eV}$ and $877.9 \mathrm{eV})$. The peaks centred around $863.6 \mathrm{eV}$ and $880.8 \mathrm{eV}$ are assigned to the satellite peaks of $\mathrm{Ni}_{2} \mathrm{p}_{3 / 2}$ and $\mathrm{Ni} 2 \mathrm{p}_{1 / 2}$. In Ni rich $\mathrm{BCs}$, more than $70 \%$ of the $\mathrm{Ni}$ atoms are oxidized. Their average oxidation state tends to increase with the $\mathrm{Ni}$ fraction, reaching a maximum in $\mathrm{Pt}_{0.3} \mathrm{Ni}_{0.7} \mathrm{BCs}$. This can be attributed to the relative stability of the $\mathrm{Ni}$ oxide and hydroxide phases; previous studies have shown that the electronic structure of $\mathrm{Ni}$ is modified by neighbouring $\mathrm{Pt}$ atoms, favouring $\mathrm{Ni}$ oxidation when these atoms are present in the BC shell. ${ }^{21}$, 22 , 29 When the Ni fraction decreases below 0.5 , the cluster structure consists of a $\mathrm{Ni}$ enriched core and a Pt enriched shell, resulting in a decrease in the $\mathrm{Ni}$ oxidation rate. XPS analysis of the deconvoluted $\mathrm{Pt}$ and Ni metal peaks in $\mathrm{Pt}_{\mathrm{x}} \mathrm{Ni}_{1-\mathrm{x}} \mathrm{BCs}$ gives a clear indication of the electronic structural modification of Pt clusters upon mixing with Ni. The Pt metal $4 \mathrm{f}$ binding energy decreases from 71.3 eV to $71.1 \mathrm{eV}$ while the Ni metal 2p binding energy increases from $852.1 \mathrm{eV}$ to $852.6 \mathrm{eV}$, 
compared to their respective monometallic counterparts. This binding energy change can be ascribed to a combined result of the charge transfer between the two elements,

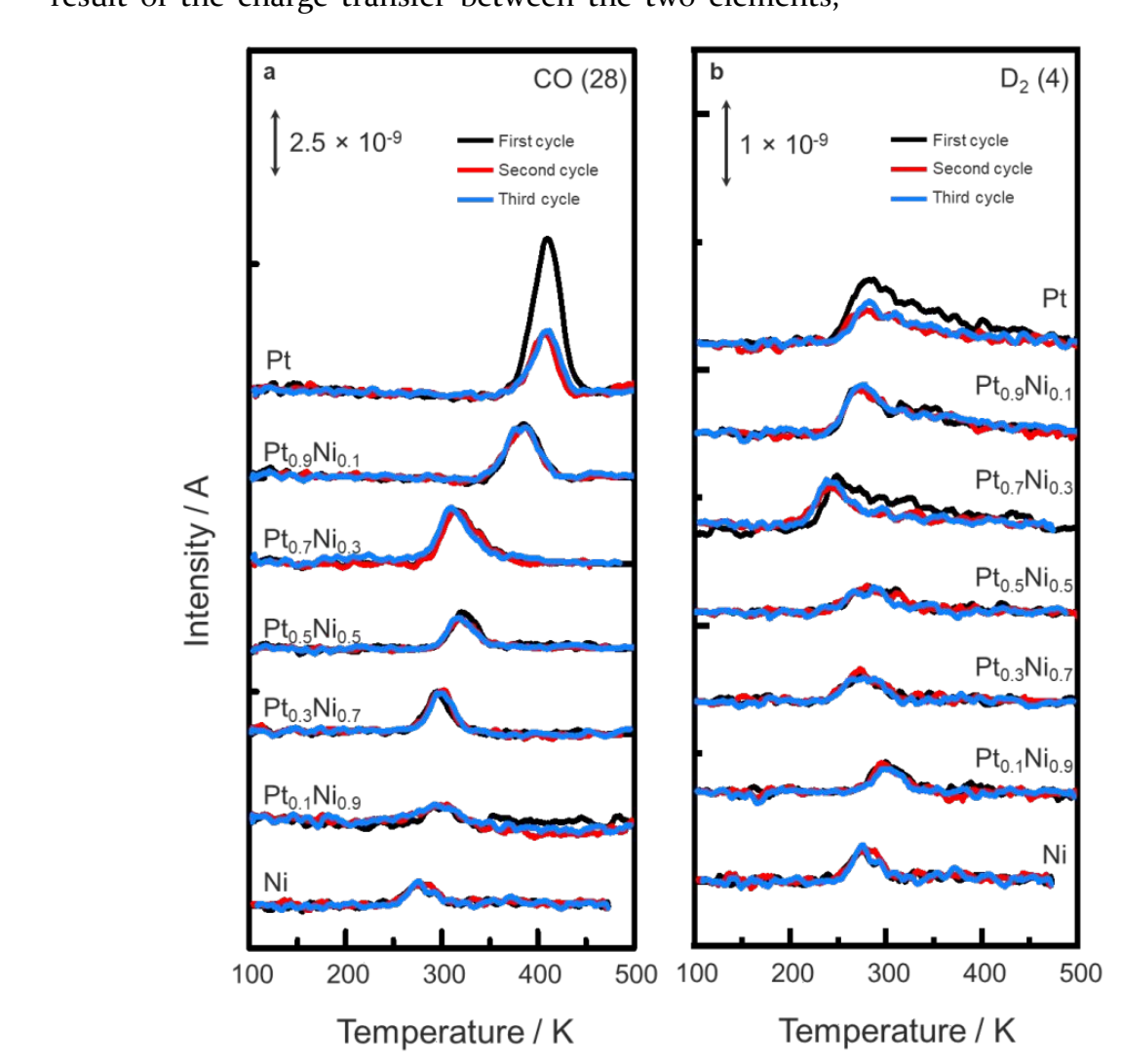

band modification by the neighbouring element, and the different oxide fractions within the BCs after air exposure. ${ }^{54}$

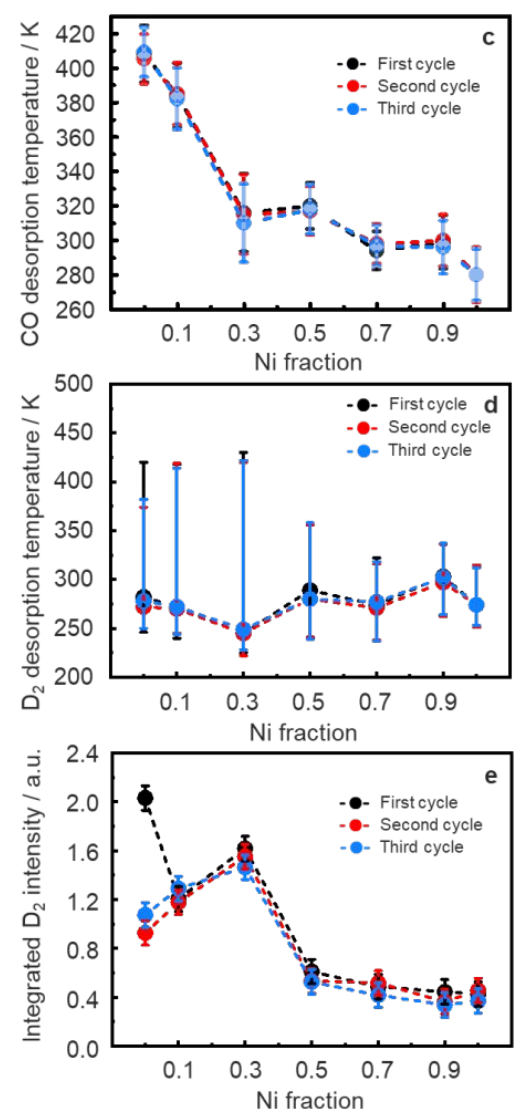

Figure 3. TPD traces of methanol decomposition on $\mathrm{Pt}_{x} \mathrm{Ni}_{1-x} \mathrm{BCs}$ of different compositions on $\mathrm{SiO}_{2}$ supports, showing the desorption of (a) CO and (b) $\mathrm{D}_{2}$. Overviews of the (c) CO and (d) $\mathrm{D}_{2}$ desorption temperature. The desorption peaks are indicated with the full circles, while the upper and lower limit of desorption are indicated with bars. (e) The integrated amount of desorbed $\mathrm{D}_{2}$ as a function of the Ni fraction in the BCs.

\section{CATALYTIC ACTIVITY OF PT ${ }_{X} \mathrm{NI}_{1-X}$ CLUSTERS}

The catalytic activity and stability of the $\mathrm{Pt}_{x} \mathrm{Ni}_{1-x}(x=1$, 0.9, 0.7, 0.5, 0.3, 0.1, o) BCs deposited on $\mathrm{SiO}_{2} / \mathrm{Si}$ wafers and without ambient exposure, were tested under UHV by TPD in the methanol dehydrogenation reaction, by ramping the temperature from $100 \mathrm{~K}$ to $500 \mathrm{~K}$ at a rate of $4 \mathrm{~K} / \mathrm{s}$ in 3 reaction cycles. The amount of hydrogen desorption is directly related to the methanol dehydrogenation catalytic activity of the $\mathrm{BCs}$, whereas the $\mathrm{CO}$ desorption temperature is correlated to the strength of the $\mathrm{CO}$ poisoning effect. (see SI for more details on TPD experiment and analysis procedures)

The TPD traces for $\mathrm{CO}$ and $\mathrm{D}_{2}$ in three subsequent cycles of methanol decomposition are shown in Figure 3, together with the dependence on the $\mathrm{Ni}$ content of the $\mathrm{CO}$ desorption temperature and the amount of $\mathrm{D}_{2}$ desorption. The exclusive detection of $\mathrm{CO}$ and $\mathrm{D}_{2}$ in the quadrupole mass spectrometer (QMS) indicates that the dominant reaction within the investigated temperature range is methanol dehydrogenation (C-D bond scission) highlighting the excellent selectivity of Pt-Ni BCs. As the same activity is measured in subsequent reaction cycles while no $\mathrm{CD}_{3}$ is formed, the $\mathrm{C}-\mathrm{O}$ bond scission pathway that ultimately forms carbon deposits and poisons the catalyst surface can be safely excluded (Figure $\mathrm{S}_{5}$ ). From the amount of $\mathrm{CO}$ and $\mathrm{D}_{2}$ desorption it is found that, except for monometallic Pt clusters, all BCs show a stable methanol dehydrogenation catalytic activity over the three reaction cycles. Although monometallic Pt clusters feature the highest activity of all samples in the first reaction cycle, their activity drops to a level similar to the other Pt-rich $\left(\mathrm{Pt}_{\mathrm{o.9}} \mathrm{Ni}_{\mathrm{o.1}}\right.$ and $\left.\mathrm{Pt}_{\mathrm{o.7}} \mathrm{Ni}_{\mathrm{o} .3}\right)$ BCs after the first cycle. All $\mathrm{Pt}_{\mathrm{x}} \mathrm{Ni}_{1-\mathrm{x}}$ compositions have a single $\mathrm{CO}$ desorption feature.

The evolution of the $\mathrm{CO}$ desorption temperature, which is related to the strength of the $\mathrm{CO}$ poisoning effect shows a systematic 2-stage decrease when the $\mathrm{Ni}$ fraction increases (Figure $3-\mathrm{c}$ ). A fast decrease is observed for Ni fractions ranging from o to 0.3 , while a slow one occurs for $\mathrm{Ni}$ fractions from 0.5 to 1 . In $\mathrm{BCs}$ with a Ni fraction of 0.3 , the $\mathrm{CO}$ poisoning effect is significantly reduced at room temperature by alloying $\mathrm{Pt}$ with $\mathrm{Ni}$ for the considered particle sizes. A low CO desorption temperature was observed in Ni rich BCs and pure Ni clusters. Since CO-Ni metal interactions are typically strong and expected to 
result in a high $\mathrm{CO}$ desorption temperature of around 400 $\mathrm{K},{ }^{6}, 57$ this strongly suggests that the $\mathrm{Ni}$ atoms on Ni-rich cluster surfaces have interacted with traces of $\mathrm{O}_{2}$ molecules inside the UHV chambers, even though the samples were transferred via a UHV transport vessel..$^{8}$ We therefore conclude that in the $\mathrm{Ni}$ rich $\mathrm{BCs}$ and pure Ni clusters, the $\mathrm{CO}$ molecules are desorbed from a Ni oxide surface.

The methanol dehydrogenation catalytic activity, defined by the integrated intensity of $D_{2}$ peaks, is stable during the three TPD cycles for all $\mathrm{Pt}_{x} \mathrm{Ni}_{1-x}$ BCs as well as for the monometallic Ni clusters. The $50 \%$ reduction in the pure Pt clusters activity in the subsequent cycles may be assigned to the lower accessibility of the reaction sites on the cluster surface. 7 The variation of the $\mathrm{D}_{2}$ desorption temperature versus the $\mathrm{BC}$ composition (Figure 3 - $\mathrm{d}$ ) shows a minimum at $\mathrm{Pt}_{\mathrm{o.7}} \mathrm{Ni}_{\text {o.3 }}$. $\mathrm{D}_{2}$ desorbs in the $250-300 \mathrm{~K}$ range indicating that $\mathrm{Ni}$ alloyed $\mathrm{Pt}$ clusters are always catalytically active below room temperature. $\mathrm{D}_{2}$ desorption also reveals the type of element present at the cluster surface. In Pt-rich $\mathrm{BC}$, the tail of the $\mathrm{D}_{2}$ desorption feature extends even to $400 \mathrm{~K}$, suggesting that $\mathrm{D}_{2}$ molecules are formed and desorbed from the $\mathrm{Pt}$ surface, 59 while no desorption higher than $350 \mathrm{~K}$ is observed in Ni-rich BCs. This is possibly due to the presence of a $\mathrm{Ni}$ enriched shell at the surface.

A volcano-like plot relating the integrated intensity of $D_{2}$ desorption to the $\mathrm{BC}$ composition (Figure 3-e) peaking at the $\mathrm{Pt}_{\mathrm{o} .7} \mathrm{Ni}_{0.3}$ composition $(+60 \%$ activity relative to pure $\mathrm{Pt}$ clusters) is observed. As the BCs catalytic activity reflects their surface properties, the nearly plateau observed for $\mathrm{Ni}$ fractions of 0.5 and up to 1 (pure Ni clusters) suggests that in these BCs the same type of atoms are present at the surface. Considering the composition-tunable phase segregated atomic arrangement observed in these BCs, a majority of $\mathrm{Ni}$ atoms are likely forming the surface of the $\mathrm{Ni}$ rich BCs. Similarly, in BCs with Ni fractions of 0.1 and 0.3 the presence of a majority of Pt atoms is expected at the cluster surface. As Pt-Ni BCs tested under methanol decomposition were not exposed to air, the nature and amount of the oxide phases at the $\mathrm{BC}$ surface is expected to differ substantially from that of their air-exposed counterparts, determined by XPS. For Ni fractions of 0.5 and up to the pure $\mathrm{Ni}$, only a superficial $\mathrm{NiO}$ layer is likely present at the cluster surface in line with the discussion above, while for BCs with $\mathrm{Ni}$ fractions of 0.1 and $0.3, \mathrm{Pt}$ atoms at the surface are expected to be mostly in a metallic state. The absence of $\mathrm{CO}_{2}$ signal in the TPD traces of methanol decomposition (see Figure S6) further substantiates that the surface of the most active $\mathrm{Pt}_{\mathrm{o} .7} \mathrm{Ni}_{0.3}$ $\mathrm{BC}$ is free of $\mathrm{Pt}$ and/or Ni oxides that could have oxidized the formed $\mathrm{CO}$ species. $\mathrm{Pt}_{\mathrm{o.7}} \mathrm{Ni}_{\mathrm{o} .3} \mathrm{BC}$, which showed the best catalytic performance combined with a reduced $\mathrm{CO}$ poisoning, was selected for further theoretical modelling of its electronic structure.

\section{DFT CALCULATIONS OF $\mathrm{PT}_{X} \mathrm{NI}_{1-X}$ CLUSTERS SURFACE AND ITS CO-PT INTERACTIONS}

In order to understand the origin of the decreased $\mathrm{CO}$ desorption temperature in $\mathrm{Ni}$ alloyed $\mathrm{Pt}$ clusters, the electronic band structure was calculated for cluster sizes of about $2 \mathrm{~nm}$ and geometries in line with the observed structures in the STEM experiments. As Ni alloyed and pure Pt clusters tested for their catalytic activity in TPD were not exposed to air, non-oxidized $\mathrm{Pt}_{459}, \mathrm{Pt}_{561}, \mathrm{Pt}_{353} \mathrm{Ni}_{106}$ and $\mathrm{Pt}_{417} \mathrm{Ni}_{144}$ were selected as representative monometallic $\mathrm{Pt}$ clusters and $\mathrm{Pt}_{\mathrm{o} .7} \mathrm{Ni}_{\mathrm{0.3}}$ BCs under methanol dehydrogenation conditions. The precise sizes correspond to closed atomic shells in FCC particles that have either the Wulff shape with small (100) facets (the 459 atom clusters) or larger (100) facets (the 561 atom clusters). Geometric details of the constructed clusters can be found in Figures 4-a, 4-b and in the method section. To model the $\mathrm{Pt}_{353} \mathrm{Ni}_{106}$ $\mathrm{BC}$, a first isomer was constructed with random Pt-Ni alloy core and Pt surface, motivated by the HAADF-STEM and TPD results. Alternative atomic orderings that were considered and locally optimized are two different fully random alloy clusters and a Ni-core/Pt-shell cluster. The locally optimized random core-Pt shell structure was found to have the lowest energy, followed by the $\mathrm{Ni}$ core/Pt-shell (+15.1 eV higher in total energy or $32.9 \mathrm{meV} /$ atom). The two random configurations are energetically the least favourable $(+16.5 \mathrm{eV}$ and $+16.6 \mathrm{eV}$, or 35.9 $\mathrm{meV} /$ atom and $36.2 \mathrm{meV} / \mathrm{atom}$, respectively). As the obtained lowest energy structure is consistent with the STEM experimental result in Error! Reference source not found., further calculations were done with the random core-Pt shell $\mathrm{BCs}$.

A rather simplified, however very successful, model used to understand the interaction of small molecules and metal surfaces is the d-band centre model, in which it is considered that on metal surfaces with a lower d-band centre (with respect to the Fermi level) adsorbates will bond less strongly. ${ }^{22}$ In this model, it is considered that upon adsorption of a molecule on a metal surface, a bonding and an antibonding state are created, and the binding energy of the surface-molecule system will depend on the electron population of the adsorbate antibonding state that lies right above the metal d-band. The less populated the antibonding state is, the stronger is the adsorbate binding energy. This idea related the d-band centre of the metal surface to the adsorbate binding energy; surfaces with a lower d-band centre will have a higher electron population of the surface-molecule antibonding state, thus decreasing its binding energy. ${ }^{60}$

In the $\mathrm{Pt}_{353} \mathrm{Ni}_{106}$ cluster (Figure 4-a) we distinguish two types of surface $\mathrm{Pt}$ atoms, those with another $\mathrm{Pt}$ atom subsurface and those with a subsurface $\mathrm{Ni}$ atom where $\mathrm{Pt}$ atoms form a skin. In the calculations of the different Pt atoms, the d-band centre of the first type of Pt atoms is $2.51 \pm 0.03 \mathrm{eV}$ (with respect to the Fermi level), whereas it is $-2.79 \pm 0.03 \mathrm{eV}$ for the second type. The range of the $\mathrm{d}-$ band centre corresponds to the different symmetry inequivalent $\mathrm{Pt}$ sites on the surface. The d-band centre averaged over all $\mathrm{Pt}$ atoms in $\mathrm{Pt}_{353} \mathrm{Ni}_{106}$ cluster is $-2.65 \mathrm{eV}$ compared to $-2.35 \pm 0.10 \mathrm{eV}$ and $-\mathbf{2 . 2 9} \pm 0.12 \mathrm{eV}$ in pure $\mathrm{Pt}_{459}$ and $\mathrm{Pt}_{561}$ clusters, respectively. The relative energy of the $\mathrm{d}-$ electrons is important for the CO binding and therefore, lowering the d-band centre of the metal should lead to a 
lower $\mathrm{CO}$ binding strength. In order to verify this argument, we calculated binding energies of the $\mathrm{CO}$ molecules on various surface sites of the clusters. The correlation between the d-band centre and the $\mathrm{CO}$ binding energy (see Figure 4-c), shows that the behaviour found for the CO binding energy on various Pt sites on these four clusters is consistent with the d-
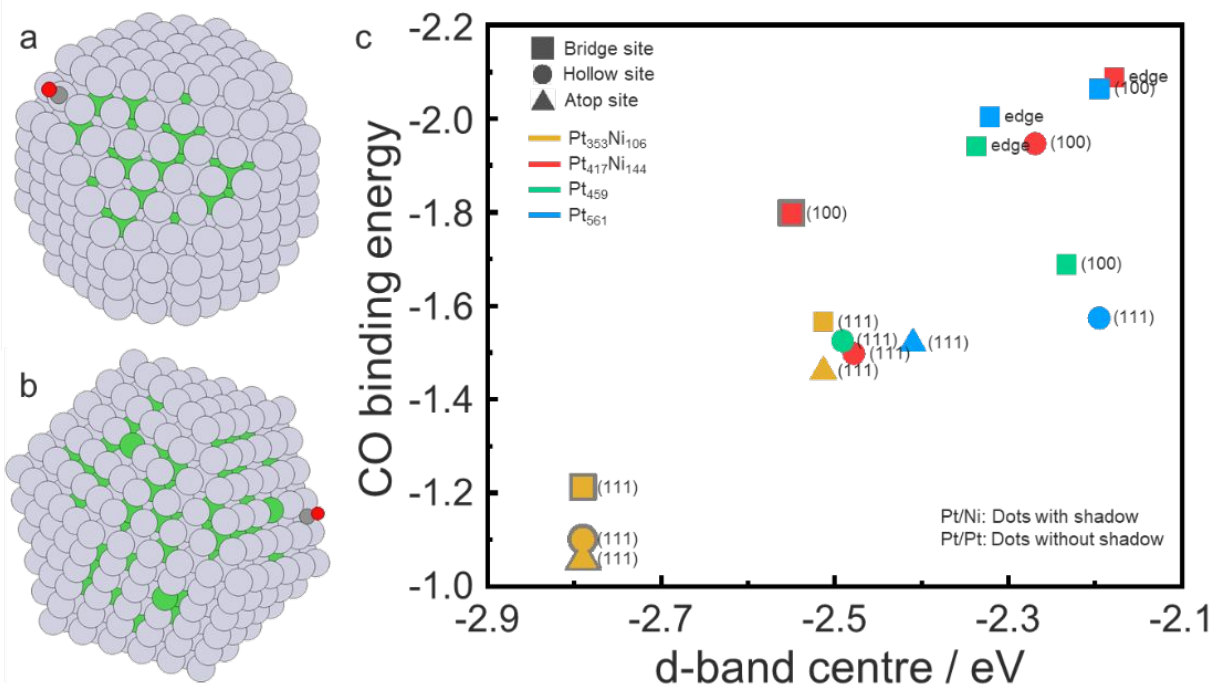

Figure 4. (a) Wulff constructed $\mathrm{Pt}_{353} \mathrm{Ni}_{106}$ clusters and (b) $\mathrm{Pt}_{417} \mathrm{Ni}_{144}$ clusters constructed with larger (100) surfaces. The CO binds on both clusters on a bridge site of a (100) Pt surface. The grey, green, dark grey, and red balls represent $\mathrm{Pt}, \mathrm{Ni}, \mathrm{C}$, and $\mathrm{O}$ atoms, respectively. (c) Overview of the $\mathrm{CO}$ binding energy as a function of the $\mathrm{d}$ band centre of the Pt atom on which the $\mathrm{CO}$ is adsorbed, for Pt atoms at the edge, (100), (111) surfaces of the Wulff constructed $\mathrm{Pt}_{353} \mathrm{Ni}_{106}$ (orange) and larger (100) surface $\mathrm{Pt}_{417} \mathrm{Ni}_{144}$ (red) BCs with either Pt or Ni subsurface atoms, as well as $\mathrm{Pt}_{459}$ (green) and $\mathrm{Pt}_{561}$ (blue) clusters. The CO adsorption on bridge site, hollow site and atop sites are presented by squares, circles and triangles, respectively. The $\mathrm{CO}$ adsorption on the Pt atoms with Ni subsurface atoms are indicated with grey shadow.

band model. A detailed table of all the calculated $\mathrm{CO}$ binding energies on different surface sites with $\mathrm{Ni}$ or $\mathrm{Pt}$ atoms at the subsurface is presented in Table Si. Although DFT calculations were performed only on two ideal clusters, we are confident that the computations captured the main trend of $\mathrm{CO}$ adsorption. Subsurface Ni reduces the $\mathrm{CO}$ binding energy on $\mathrm{Pt}$, whether it is located on the flat 111 or more open 100 surfaces as well as on the edge sites. Surface defects like vacancies or adatoms are expected to alter the absolute values of the $\mathrm{CO}$ binding energy but very unlikely modify the general trend of a reduced $\mathrm{CO}$ binding energy in presence of subsurface $\mathrm{Ni}$ atoms. The d-electron population analysis of the $\mathrm{BCs}$ also reveals a substantial modification of the electronic structure of skin $\mathrm{Pt}$ atoms by neighbouring subsurface $\mathrm{Ni}$ atoms. In particular, a Löwdin population analysis ${ }^{61}$ shows a reduction of their d-electron population by nearby $\mathrm{Ni}$ atoms, which may be in line with the model proposed by Toda et al. ${ }^{62}$ The correlation between d-electron population and $\mathrm{CO}$ binding energy is presented in Figure $\mathrm{S}_{7}$ and Table S2. In general, independently of whether the Pt atoms are located at (100) or (111) surfaces, or at edge sites, the $\mathrm{CO}$ binding energy is lower if a $\mathrm{Ni}$ atom is present at the subsurface. Therefore, the decreased $\mathrm{CO}$ desorption temperature on $\mathrm{Pt}_{x} \mathrm{Ni}_{1-x}$ BCs can be assigned to local modifications of the d-band electronic structure of surface Pt atoms forming a skin, induced by the presence of subsurface $\mathrm{Ni}$, which results in a weakened CO-Pt interaction. This is in excellent agreement with the observed reduced $\mathrm{CO}$ desorption temperature with $\mathrm{Ni}$ fraction in the methanol decomposition TPD experiments.

A maximum in the methanol activity is reached for the same $\mathrm{Pt}_{0.7} \mathrm{Ni}_{\text {o.3 }}$ cluster composition suggesting that it may be directly related to the $\mathrm{CO}$ poisoning of the clusters surfaces. ${ }^{28,63}$ Although our calculations show that the first methanol dissociation reaction intermediate $\mathrm{HOCH}_{2}$ binds well to the Pt-skin surface of $\mathrm{Pt}_{353} \mathrm{Ni}_{106}$ clusters, the calculated methanol binding energy on the same cluster is almost site independent and has a small value of - $0.1 \mathrm{eV}$, compared to $-0.33 \mathrm{eV}$ for pure $\mathrm{Pt}(111) .^{64}$ This is in line with previous calculations that showed that downshifting the $\mathrm{Pt}$ d-band centre not only results in weakening the $\mathrm{CO}$ binding energy but also that of the methanol itself. As the dissociative adsorption of methanol involving a firsthydrogen extraction by $\mathrm{O}-\mathrm{H}$ or $\mathrm{C}-\mathrm{H}$ bond scission is regarded as the rate-determining step of methanol dehydrogenation on Pt surfaces, ${ }^{64}, 65$ a reduced binding energy of methanol to $\mathrm{Pt}$ is not expected to favour its dissociation. ${ }^{6}$ This suggests that the increased methanol activity observed for the $\mathrm{x}=0.3$ composition is more related to the reduction of the $\mathrm{CO}$ poisoning that blocks the available Pt active sites at the surface of the cluster rather than to an increase in the intrinsic methanol dehydrogenation activity in line with the reported 6o\% activity increase of $\mathrm{Pt}_{0.7} \mathrm{Ni}_{0.3} \mathrm{BCs}$ in comparison to $\mathrm{Pt}$ clusters. This would be in good agreement with previous 
work that identified $\mathrm{OH}$ and $\mathrm{CO}$ binding free energies as the main descriptors of the methanol dehydrogenation on metal surfaces in DMFCs. ${ }^{66}$ As the reaction was carried out in UHV, the enhanced methanol activity in this work is then expected to be mainly described by the $\mathrm{CO}$ binding free energy. Calculated $\mathrm{CO}$ desorption energies $\left(\mathrm{E}_{\mathrm{d}}\right)$ from TPD experiments are in line with the $\mathrm{CO}$ binding energies computed by DFT, therefore confirming that our Pt-Ni catalysts dehydrogenate methanol selectively by forming exclusively $\mathrm{CO}$ and $\mathrm{D}_{2}$, excluding the formation of $\mathrm{CD}_{4}$ (See SI).

This Pt-skin with subsurface $\mathrm{Ni}$ architecture at the surface of $2 \mathrm{~nm} \mathrm{Pt}_{\mathrm{o} .7} \mathrm{Ni}_{\mathrm{O}_{3}} \mathrm{BCs}$ resembles closely those identified at the extended surfaces of Pt-Ni alloyed electrocatalysts as highly active surfaces for the ORR that occurs at the cathode of the MFC. ${ }^{28}$ Interestingly, this specific Pt-skin surface architecture forms preferentially on electrodes with the similar $\mathrm{Pt}_{3} \mathrm{Ni}$ composition corresponding to the most active $\mathrm{BCs}$ identified in this work. ${ }^{28-31}$ The computed d-band shift of ca. $-\mathbf{2 . 7} \mathrm{eV}$ for the $\mathrm{Pt}$ skin on a $\mathrm{Pt}_{3} \mathrm{Ni}$ alloy surface that corresponds to an optimal adsorption strength of the $\mathrm{OH}$ molecules in the ORR are in line with the corresponding value of $-2.65 \mathrm{eV}$ averaged over all Pt atoms and $-2.8 \mathrm{eV}$ for the (111) facet sites of $\mathrm{Pt}_{353} \mathrm{Ni}_{106} \mathrm{BCs}$ calculated in this work. ${ }^{28}$ The corresponding d-band shift of $-2.5 \mathrm{eV}$ for the extended surfaces of pure $\mathrm{Pt}^{28}$ is also in line with the values of $-2.5 \mathrm{eV}$ computed here for the (111) facet sites of pure $\mathrm{Pt}_{561}$ and $\mathrm{Pt}_{459}$, as well as the $\mathrm{Pt}$ surface atoms with $\mathrm{Pt}$ subsurface in $\mathrm{Pt}_{353} \mathrm{Ni}_{106}$ and $\mathrm{Pt}_{417} \mathrm{Ni}_{144}$ clusters. This demonstrates that thermodynamically stable highly catalytic active Pt skin architectures can be created on the nanoscale surfaces of small BCs with the CBD technology. This is achieved by tuning the $\mathrm{BC}$ composition to $\mathrm{Pt}_{3} \mathrm{Ni}$ and taking advantage of the composition-dependent segregation profile resulting from the $\mathrm{BCs}$ nucleation mechanism, likely to be applicable to a variety of binary systems besides $\mathrm{Pt}-\mathrm{Ni} .^{28}$

These results also suggest that the Pt-skin architecture that forms at the surface of $\mathrm{Pt}_{\mathrm{o} .7} \mathrm{Ni}_{0.3}$ clusters feature not only an enhanced catalytic activity in the methanol dehydrogenation $(+60 \%$ relative to pure Pt clusters) at the anode, but also in the ORR occurring at the cathode of the MFCs. As for the ORR, the relationship between the specific methanol dehydrogenation activity and the dband centre position on the Pt-skin surfaces exhibits a volcano-like shape. The relative methanol dehydrogenation activity of $\mathrm{Pt}_{\mathrm{o} .9} \mathrm{Ni}_{\mathrm{o} .1} \mathrm{BCs}(+20 \%$ relative to pure Pt clusters) suggests the formation of a Pt-surface with a Pt subsurface configuration with an estimated $\mathrm{d}$ centre downshift of $-2.5 \mathrm{eV}$, while for $\mathrm{Pt}_{0.5} \mathrm{Ni}_{0.5}, \mathrm{Pt}_{0.3} \mathrm{Ni}_{0.7}$, $\mathrm{Pt}_{0.1} \mathrm{Ni}_{\text {o.9 }}$ BCs showed a reduced activity $(-50$ to $-60 \%$ relative to pure $\mathrm{Pt}$ clusters) due to the presence of an increasing amount of $\mathrm{Ni}$ oxide at their surfaces. As Pt-skins stable under (electro)chemical conditions ${ }^{28}, 34$ can be generally obtained by a simple mild annealing of bimetallic $\mathrm{Pt}_{3} \mathrm{Ni}$ (nano)structures, ${ }^{28},{ }^{2}$ we expect that the more oxidised surfaces of air-exposed $\mathrm{Pt}_{3} \mathrm{Ni}$ BCs measured by XPS can be easily transformed into a stable Pt-skin architecture similar to that obtained in UHV after the same treatment.

CBD fabrication that enables a precise tuning of the electronic properties of bi-(multi-) metallic nanoparticles, may allow the emergence of a new generation of bi-(multi) metallic systems with nanoscale-engineered well-defined Pt skin surfaces. These Pt-based (electro) catalysts with reduced $\mathrm{Pt}$ content show an enhanced catalytic activity in anode-related methanol dehydrogenation as well as in the cathode ORR, and therefore, can contribute to lowering the Pt loadings in polymer electrolyte membrane fuel cells and facilitate their utilisation as sustainable and clean energy conversion devices.

\section{CONCLUSIONS}

The atomic arrangement and the catalytic activity of $\mathbf{2 . 0}$ $n m$ gas phase $\mathrm{Pt}_{x} \mathrm{Ni}_{1-x} \mathrm{BC}$ s deposited on TEM grids and $\mathrm{SiO}_{2}$ supports were experimentally studied by HAADF-STEM, XPS and TPD. HAADF-STEM showed that these BCs have composition-tunable atomic arrangements with minority element enriched core and majority element dominated shell structure, most likely stemming from their nucleation mechanism. The BCs oxidation and phase composition revealed by XPS confirmed their phase-segregated structure. TPD under UHV conditions show that methanol dehydrogenation via $\mathrm{C}-\mathrm{D}$ and $\mathrm{O}-\mathrm{D}$ bond scission occurs on the cluster surface, with $\mathrm{CO}$ and $\mathrm{D}_{2}$ as products. A volcanolike methanol dehydrogenation catalytic activity, triggered by a strong reduction of $\mathrm{CO}$ poisoning effect, is obtained by alloying $\mathrm{Pt}$ with $\mathrm{Ni}$ and peaks at the $\mathrm{Pt}_{\mathrm{o} .7} \mathrm{Ni}_{\mathrm{o.3}}$ composition. This is attributed by DFT calculations to a Ptskin with subsurface $\mathrm{Ni}$, where the local modifications of the Pt d-band, induced by $\mathrm{Ni}$, leads to a high methanol dehydrogenation activity and weakened Pt-CO interaction, in agreement with the d-band centre model. We demonstrate a clear composition-tuned catalytic activity and $\mathrm{CO}$ poisoning effect of $\mathrm{Pt}-\mathrm{Ni} \mathrm{BCs}$ in the methanol decomposition reaction, explained by a composition-tuned segregation profile resulting directly from the BC nucleation mechanism. Tuning the BCs surface architecture to obtain a Pt-skin with subsurface Ni atoms, using the size and composition precision of the CBD fabrication, offers a new direction to designing long lifetime and highly active methanol fuel cell Pt-based anode but also cathode catalysts.

\section{METHODS/EXPERIMENTAL DETAILS}

Production of $\mathbf{P t}_{\mathbf{x}} \mathbf{N i}_{1-x}$ clusters. Composition controlled $\mathrm{Pt}_{x} \mathrm{Ni}_{1-x}(x=0,0.1,0.3,0.5,0.7,0.9,1)$ BCs were produced by a combination of pulsed laser (10 Hz, Nd:YAG lasers) ablation of $\mathrm{Pt}_{x} \mathrm{Ni}_{1-x}$ (ACI alloy, purity 99.5\%) plate targets and inert gas (He, purity 99.9999\%) condensation. ${ }^{1}$ The size distribution of the BCs was monitored by reflectron time-of-flight (RTOF) mass spectrometry and optimized to have an average size around $2.0 \pm 1.4 \mathrm{~nm}$. Following a supersonic expansion into vacuum, the molecular beam of $\mathrm{Pt}_{x} \mathrm{Ni}_{1-x}$ BCs was guided to the deposition chamber and soft-landed $(\sim 500 \mathrm{~m} / \mathrm{s})$ on TEM grids and on $\mathrm{SiO}_{2} / \mathrm{Si}$ (10o) substrates, for STEM and TPD 
measurements, respectively. ${ }^{67}$ The substrates were held at room temperature and equivalent atomic coverages of $1 \mathrm{ML}$ for TEM and $5 \mathrm{ML}$ for TPD were deposited. Assuming the cluster diameter is $2 \mathrm{~nm}$, the projected area coverage of 1 ML and 5 ML will be around $5 \%$ and $25 \%$, respectively. The flux of the BCs was monitored by a quartz crystal microbalance and the $\mathrm{BC}$ coverage was controlled by the deposition time assuming a constant cluster flux.

Structures of the $\mathrm{Pt}_{x} \mathrm{Ni}_{1-x}$ clusters and atomic arrangements. Atomic resolution STEM imaging was performed by a FEI Titan G2 8o-200 Chemi-STEM operating at $200 \mathrm{keV}$ and equipped with spherical aberration (Cs) probe corrector, as well as a high-angle annular dark-field (HAADF) detector. The cluster size distributions of the $\mathrm{Pt}_{x} \mathrm{Ni}_{1-x} \mathrm{BC}$ sere measured with low magnification in a sample of more than 300 BCs. The cluster size was determined by measuring the diameter cross-section of individual clusters. Identification of a possible core-shell structure was obtained by the Zcontrast of HAADF-STEM ( $Z$ is the elemental atomic number). The HAADF-STEM intensity is proportional to $\mathrm{Z}^{1.5}$ with the camera length employed.53 The large difference of the atomic number between $\mathrm{Pt}$ and $\mathrm{Ni}\left(\mathrm{Z}_{\mathrm{Pt}}=\right.$ $78 ; \mathrm{Z}_{\mathrm{Ni}}=28$ ) allows distinguishing the elemental atomic arrangement within the clusters directly from the HAADFSTEM image intensity contrast. STEM image analysis was carried out with the imageJ Fiji software. The intensity profile of each cluster was obtained by first identifying the position of the centre through averaging, and then binning the intensity in polar coordinates as a function of the radial distance to the centre.

Methanol decomposition on $\mathrm{Pt}_{x} \mathrm{Ni}_{1-x} / \mathrm{SiO}_{2} / \mathrm{Si}(100)$. Boron doped amorphous $\mathrm{SiO}_{2} / \mathrm{Si}(100)$ wafers were heated up with direct resistive heating and cleaned more than three times by a flash-heating process to $700 \mathrm{~K}$ to desorb all contaminations in an UHV chamber (base pressure $6 \times$ $10^{-10}$ mbar) dedicated to the TPD experiments. The desorbed contaminations were monitored by a quadruple mass spectrometer (QMS), considering the masses of $\mathrm{H}_{2} \mathrm{O}$ (18), $\mathrm{CO} / \mathrm{N}_{2}(28), \mathrm{O}_{2}(32), \mathrm{Ar}(40), \mathrm{CO}_{2}(44)$. The sample cleaning process was terminated at the point the signal of the listed masses was reduced to the noise level. The methanol-d $4\left(\mathrm{CD}_{3} \mathrm{OD}\right)$ was purified in an UHV compatible glass test tube by repeated freeze-pump-thaw cycles to remove all the gases in the test tube and the vacuum gas lines. The methanol-d 4 was introduced into the UHV chamber by a leak valve and was guided to the sample surface by a dozer tube. The cleaned $\mathrm{SiO}_{2}$ sample was exposed to $5 \mathrm{~L}$ of methanol-d 4 at $100 \mathrm{~K}$. The methanol-d 4 desorption was conducted with PID controlled linear heating using a $4 \mathrm{~K} / \mathrm{s}$ ramping rate and the molecule desorption was monitored by the QMS considering all possible cracking patterns. No $\mathrm{C}-\mathrm{H}, \mathrm{C}-\mathrm{O}$ and $\mathrm{O}-\mathrm{H}$ bond scission was observed on the clean $\mathrm{SiO}_{2}$ surface.

The cleaned $\mathrm{SiO}_{2} / \mathrm{Si}$ (100) samples were then transferred in a home-built UHV transport vessel with base pressure in the $10^{-10}$ mbar range to the CBD chamber with base pressure in the $10^{-9}$ mbar range. After deposition of the $\mathrm{Pt}_{x} \mathrm{Ni}_{1-x} \mathrm{BC}$ s on the $\mathrm{SiO}_{2} / \mathrm{Si}$ (100) substrates, the samples were transferred back to the TPD setup for methanol decomposition experiments. The samples were cooled down to $100 \mathrm{~K}$ by a flow of liquid nitrogen $\left(\mathrm{LN}_{2}\right)$ in flexible stainless steel tubes and exposed to $5 \mathrm{~L}$ methanol- $\mathrm{d}_{4}$ for saturation adsorption of methanol-d 4 on the surface. TPD spectra were taken in the $100 \mathrm{~K}$ to $500 \mathrm{~K}$ temperature range using a $4 \mathrm{~K} / \mathrm{s}$ ramping rate. The catalytic experiments were repeated 3 times for each same sample to characterize the stability and catalytic activity.

Electronic structure and oxidation state characterizations. XPS experiments were performed at room temperature and under UHV conditions (base pressure $1.6 \times 10^{-9} \mathrm{mbar}$ ), but after exposure of the samples to air, in a Kratos Axis Supra system with a monochromatized $\mathrm{Al} \mathrm{K \alpha}$ X-ray source $(1486.6 \mathrm{eV})$ operated at $10 \mathrm{~mA}$. The spectra were collected by hemispherical analyser with passing energy of $160 \mathrm{eV}$ and $20 \mathrm{eV}$ for the wide scan and high-resolution spectra, respectively. The spectra were aligned to the adventitious carbon peak $C$ is at $284.8 \mathrm{eV}$. The deconvolution and fitting of the peaks was done with CasaXPS software. ${ }^{68}$ The following spin-orbit coupling constraints were considered: peak separations of $17.3 \mathrm{eV}$ and $3.35 \mathrm{eV}$ and peak area ratios of $2 / 3$ and $3 / 4$ for $\mathrm{Ni} 2 \mathrm{p}$ and Pt $4 \mathrm{f}$, respectively.

DFT calculations on the electronic structures and $\mathrm{CO}$ / methanol - Pt interactions. The $\mathrm{Pt}_{459}, \mathrm{Pt}_{561}, \mathrm{Pt}_{353} \mathrm{Ni}_{106}$ and $\mathrm{Pt}_{417} \mathrm{Ni}_{144}$ clusters were modelled by density functional theory (DFT) with the $\mathrm{CP}_{2} \mathrm{~K}$ code. ${ }^{69-71}$ The BLYP functional with GTH pseudopotentials ${ }^{72}$ (18 active electrons) was used for both Ni and Pt. The DZVP-MOLOPT-SR basis was employed. The 459- and 561-atom clusters were placed in cubes with edge sizes of $29 \AA$ A side and $27 \AA$ A respectively. Both the local atomic structure and total spin were optimized. The diagonalization method with the Kerker mixing was used in the electronic structure optimization. The charge decomposition analysis was performed using the Hirshfeld, 73 Bader, Löwdin, and Mulliken methods. The charge decomposition analysis is shown in Table S3. Two different type of random core-Pt shell clusters were constructed. The Wulff constructed $\mathrm{Pt}_{353} \mathrm{Ni}_{106}$ cluster (diameter ca. $2.4 \mathrm{~nm}$ ) was modelled with Pt surface tensions of $1.49 \mathrm{~J} / \mathrm{m}^{2}$ for (111) and $1.81 \mathrm{~J} / \mathrm{m}^{2}$ for (100) from Ref S1. (Figure 4-a). This lead to very small (100) facets of only four atoms. $\mathrm{Pt}_{417} \mathrm{Ni}_{144}$ cluster (diameter ca. $2.7 \mathrm{~nm}$ ) was generated with larger (100) facets (Figure 4-b). Pure Pt cluster has a slightly higher energy, namely $4.5 \mathrm{meV} / \mathrm{atom}$.

\section{ASSOCIATED CONTENT}

The Supporting Information is available free of charge on the ACS Publications website at DOI: 10.1021/acs.chemmater.xxxxx. It contains Figures $S_{1}$ to $S_{7}$, Tables $\mathrm{S}_{1}$ to $\mathrm{S}_{3}$ and Additional material including a comparison of the preparation and structures of $\mathrm{Au}-\mathrm{Ag} \mathrm{BCs}$ with Pt-Ni BCs, the TPD experiment and analysis procedures and details on the DFT calculations.

\section{AUTHOR INFORMATION}

\section{Corresponding Authors}

* Ting-Wei Liao: tiwei@dtu.dk 
* Didier Grandjean: didier.grandjean@kuleuven.be

* Peter Lievens: peter.lievens@kuleuven.be

\section{Present Addresses}

† Section for Surface Physics and Catalysis, Department of Physics, Technical University of Denmark, 280o Kgs Lyngby, Denmark

\section{Author Contributions}

$\ddagger$ T.-W. L and A.Y. contributed equally to this manuscript. P. L., E. J., D. G., A. Y. and T.-W. L. designed the project. K.-J. $\mathrm{H}$ and T.-W. L. designed, constructed, and studied the reactivity in the TPD setup. A. Y., Y. N. and T.-W. L. synthesized and deposited bimetallic clusters. X.-K. W., M. H., R. E. D.-B. carried out the STEM measurements. J. V. and R. E. P. carried out the XPS measurements. P. F. and K. L. performed the DFT calculations. All authors contributed to editing and proofreading of the manuscript.

\section{Notes}

The authors declare no competing financial interests.

\section{ACKNOWLEDGMENT}

The research leading to these results has received funding from the European Union's Seventh Framework Programme

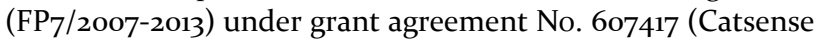
project). P.F. acknowledges the FWO for a postdoctoral grant. A.Y. and E.J. acknowledge the KU Leuven Research Council (CELSA/18/032). The Swansea team would like to acknowledge the assistance provided by Swansea University College of Engineering AIM Facility, which was funded in part by the EPSRC (EP/Mo28267/1), the European Regional Development Fund through the Welsh Government (80708) and the Ser Solar project via Welsh Government. The Swansea team, K.L., X.-K.W., M.H. and R.E.D.-B. acknowledge the European Union's Horizon 2020 Research and Innovation Program under grant agreement No. 686053 (CritCat Project).

\section{REFERENCES}

(1) Olah, G. A., Beyond Oil and Gas: The Methanol Economy. Angew. Chem. Int. Ed. 2005, 44 (18), 2636-2639.

(2) Gumber, S.; Gurumoorthy, A. V. P., Chapter 25 Methanol Economy Versus Hydrogen Economy A2 - Basile, Angelo. In Methanol, Dalena, F., Ed. Elsevier: Amsterdam, Netherlands, 2018; Chapter 25, pp 661-674.

(3) Hung, T.-C.; Liao, T.-W.; Liao, Z.-H.; Hsu, P.-W.; Cai, P.Y.; Lee, H.; Lai, Y.-L.; Hsu, Y.-J.; Chen, H.-Y.; Wang, J.-H.; Luo, M.F., Dependence on Size of Supported Rh Nanoclusters in the Decomposition of Methanol. ACS Catal. 2015, 5 (7), 4276-4287.

(4) Rostrup-Nielsen, J. R.; Nielsen, R., Fuels and Energy for the Future: The Role of Catalysis. Catal. Rev. 2oo4, 46 (3-4), 247270.

(5) Debe, M. K., Electrocatalyst Approaches and Challenges for Automotive Fuel Cells. Nature 2012, 486 (7401), 43-51.

(6) Chao, C.-S.; Liao, T.-W.; Wang, C.-X.; Li, Y.-D.; Hung, T.-C.; Luo, M.-F., Obstruction by CO of the Decomposition of Methanol on Pt Nanoclusters on a Thin Film of $\mathrm{Al}_{2} \mathrm{O}_{3} / \mathrm{NiAl}_{(100)}$. Appl. Surf. Sci. 2014, 293, 352-358.

(7) Chao, C.-S.; Li, Y.-D.; Liao, T.-W.; Hung, T.-C.; Luo, M.F., Decomposition of Methanol on Partially AluminaEncapsulated Pt Nanoclusters Supported on Thin Film $\mathrm{Al}_{2} \mathrm{O}_{3} / \mathrm{NiAl}(100)$. Appl. Surf. Sci. 2014, 311, 763-769.

(8) Glüsen, A.; Dionigi, F.; Paciok, P.; Heggen, M.; Müller, M.; Gan, L.; Strasser, P.; Dunin-Borkowski, R. E.; Stolten, D.,
Dealloyed PtNi-Core-Shell Nanocatalysts Enable Significant Lowering of Pt Electrode Content in Direct Methanol Fuel Cells. ACS Catal.. 2019, 3764-3772.

(9) Ehteshami, S. M. M.; Chan, S. H., A Review of ElectroCatalysts with Enhanced CO Tolerance and Stability for Polymer Electrolyte Membarane Fuel Cells. Electrochim. Acta 2013, 93, 334-345.

(10) Baschuk, J. J.; Li, X. G., Carbon Monoxide Poisoning of Proton Exchange Membrane Fuel Cells. Int. J. Energ. Res. 2001, 25 (8), 695-713.

(11) Liu, J. L.; Lucci, F. R.; Yang, M.; Lee, S.; Marcinkowski, M. D.; Therrien, A. J.; Williams, C. T.; Sykes, E. C. H.; FlytzaniStephanopoulos, M., Tackling CO Poisoning with Single-Atom Alloy Catalysts. J. Am. Chem. Soc. 2016, 138 (20), 6396-6399.

(12) Kizhakevariam, N.; Stuve, E. M., Promotion and Poisoning of the Reaction of Methanol on Clean and Modified Platinum (100). Surf. Sci. 1993, 286 (3), 246-26o.

(13) Kramer, Z. C.; Gu, X. K.; Zhou, D. D. Y.; Li, W. X.; Skodje, R. T., Following Molecules through Reactive Networks: Surface Catalyzed Decomposition of Methanol on $\mathrm{Pd}(111), \operatorname{Pt}(111)$, and Ni(111). J. Phys. Chem. C 2014, 118 (23), 12364-12383.

(14) Sexton, B. A., Methanol Decomposition on Platinum (111). Surf. Sci. 1981, 102 (1), 271-281.

(15) Stottlemyer, A. L.; Ren, H.; Chen, J. G., Reactions of Methanol and Ethylene Glycol on Ni/Pt: Bridging the Materials Gap between Single Crystal and Polycrystalline Bimetallic Surfaces. Surf. Sci. 2009, 603 (16), 2630-2638.

(16) Feng, Y. Y.; Bi, L. X.; Liu, Z. H.; Kong, D. S.; Yu, Z. Y., Significantly Enhanced Electrocatalytic Activity for Methanol Electro-Oxidation on $\mathrm{Ag}$ Oxide-Promoted $\mathrm{PtAg} / \mathrm{C}$ Catalysts in Alkaline Electrolyte. J. Catal. 2012, 290, 18-25.

(17) Hu, J. E.; Liu, Z. F.; Eichhorn, B. W.; Jackson, G. S., CO Tolerance of Nano-Architectured Pt-Mo Anode Electrocatalysts for PEM Fuel Cells. Int. J. Hydrogen Energy 2012, 37 (15), 1126811275.

(18) Kim, J. H.; Choi, S. M.; Nam, S. H.; Seo, M. H.; Choi, S. H.; Kim, W. B., Influence of Sn Content on PtSn/C Catalysts for Electrooxidation of C-1-C-3 Alcohols: Synthesis, Characterization, and Electrocatalytic Activity. Appl. Catal., B 2008, 82 (1-2), 89-102.

(19) Rocha, T. A.; Ibanhi, F.; Colmati, F.; Linares, J. J.; Paganin, V. A.; Gonzalez, E. R., Nb as an Influential Element for Increasing the $\mathrm{CO}$ Tolerance of PEMFC Catalysts. J. Appl. Electrochem. 2013, 43 (8), 817-827.

(20) Liao, M. S.; Cabrera, C. R.; Ishikawa, Y., A Theoretical Study of CO Adsorption on Pt, Ru and Pt-M (M = Ru, Sn, Ge) Clusters. Surf. Sci. 200o, 445 (2-3), 267-282.

(21) Kitchin, J. R.; Norskov, J. K.; Barteau, M. A.; Chen, J. G., Modification of the Surface Electronic and Chemical Properties of Pt(111) by Subsurface 3d Transition Metals. J. Chem. Phys. 20o4, 120 (21), 10240-10246.

(22) Norskov, J. K.; Abild-Pedersen, F.; Studt, F.; Bligaard, T., Density Functional Theory in Surface Chemistry and Catalysis. Proc. Natl. Acad. Sci. U.S.A. 2011, 108 (3), 937-943.

(23) Skoplyak, O.; Menning, C. A.; Barteau, M. A.; Chen, J. G. G., Experimental and Theoretical Study of Reactivity Trends for Methanol on $\mathrm{Co} / \mathrm{Pt}(111)$ and $\mathrm{Ni} / \mathrm{Pt}(111)$ Bimetallic Surfaces. J. Chem. Phys. 2007, 127 (11).

(24) Garcia-Muelas, R.; Li, Q.; Lopez, N., Density Functional Theory Comparison of Methanol Decomposition and Reverse Reactions on Metal Surfaces. ACS Catal. 2015, 5 (2), 1027-1036.

(25) Guo, W. L.; Tian, W. Q.; Lian, X.; Liu, F. L.; Zhou, M.; Xiao, P.; Zhang, Y. H., A Comparison of the Dominant Pathways for the Methanol Dehydrogenation to $\mathrm{CO}$ on $\mathrm{Pt}_{7}$ and Pt7-xNix $(\mathrm{x}=1,2,3)$ Bimetallic Clusters: A DFT Study. Comput. Theor. Chem. 2014, 1032, 73-83.

(26) Ferrari, P.; Molina, L. M.; Kaydashev, V. E.; Alonso, J. A.; Lievens, P.; Janssens, E., Controlling the Adsorption of Carbon 
Monoxide on Platinum Clusters by Dopant-Induced Electronic Structure Modification. Angew. Chem., Int. Ed. 2016, 55 (37), 1105911063.

(27) Ferrari, P.; Vanbuel, J.; Tam, N. M.; Nguyen, M. T.; Gewinner, S.; Schollkopf, W.; Fielicke, A.; Janssens, E., Effects of Charge Transfer on the Adsorption of CO on Small MolybdenumDoped Platinum Clusters. Chem. - Eur. J. 2017, 23 (17), 4120-4127.

(28) Stamenkovic, V. R.; Mun, B. S.; Arenz, M.; Mayrhofer, K. J. J.; Lucas, C. A.; Wang, G. F.; Ross, P. N.; Markovic, N. M., Trends in Electrocatalysis on Extended and Nanoscale Pt-Bimetallic Alloy Surfaces. Nat. Mater. 2007, 6 (3), 241-247.

(29) Stamenkovic, V. R.; Fowler, B.; Mun, B. S.; Wang, G. F.; Ross, P. N.; Lucas, C. A.; Markovic, N. M., Improved Oxygen Reduction Activity on $\mathrm{Pt}_{3} \mathrm{Ni}(111)$ via Increased Surface Site Availability. Science 2007, 315 (5811), 493-497.

(30) Stamenkovic, V.; Mun, B. S.; Mayrhofer, K. J. J.; Ross, P. N.; Markovic, N. M.; Rossmeisl, J.; Greeley, J.; Norskov, J. K., Changing the Activity of Electrocatalysts for Oxygen Reduction by Tuning the Surface Electronic Structure. Angew. Chem., Int. Ed. 2006, 45 (18), 2897-2901.

(31) Huang, J.-F.; Tseng, P.-K., High Performance Layer-byLayer Pt3Ni(Pt-Skin)-Modified Pd/C for the Oxygen Reduction Reaction. Chem. Sci. 2018, 9 (28), 6134-6142.

(32) Becknell, N.; Kang, Y.; Chen, C.; Resasco, J.; Kornienko, N.; Guo, J.; Markovic, N. M.; Somorjai, G. A.; Stamenkovic, V. R.; Yang, P., Atomic Structure of Pt3Ni Nanoframe Electrocatalysts by in Situ X-ray Absorption Spectroscopy. J. Am. Chem. Soc. 2015, 137 (50), 15817-15824.

(33) Zhang, B.-W.; Zhang, Z.-C.; Liao, H.-G.; Gong, Y.; Gu, L.; Qu, X.-M.; You, L.-X.; Liu, S.; Huang, L.; Tian, X.-C.; Huang, R.; Zhu, F.-C.; Liu, T.; Jiang, Y.-X.; Zhou, Z.-Y.; Sun, S.-G., Tuning PtSkin to Ni-Rich Surface of Pt3Ni Catalysts Supported on Porous Carbon for Enhanced Oxygen Reduction Reaction and Formic Electro-Oxidation. Nano Energy 2016, 19, 198-209.

(34) Liu, J.; Lan, J.; Yang, L.; Wang, F.; Yin, J., PtM (M = Fe, $\mathrm{Co}, \mathrm{Ni}$ ) Bimetallic Nanoclusters as Active, Methanol-Tolerant, and Stable Catalysts toward the Oxygen Reduction Reaction. ACS Sustainable Chem. Eng. 2019, 7 (7), 6541-6549.

(35) Liang, G. F.; He, L. M.; Arai, M.; Zhao, F. Y., The PtEnriched PtNi Alloy Surface and its Excellent Catalytic Performance in Hydrolytic Hydrogenation of Cellulose. ChemSusChem 2014, 7 (5), 1415-1421.

(36) Jia, Q. Y.; Segre, C. U.; Ramaker, D.; Caldwell, K.; Trahan, M.; Mukerjee, S., Structure-Property-Activity Correlations of Pt-Bimetallic Nanoparticles: A Theoretical Study. Electrochim. Acta 2013, 88, 604-613.

(37) Dutta, A.; Ouyang, J. Y., Ternary NiAuPt Nanoparticles on Reduced Graphene Oxide as Catalysts toward the Electrochemical Oxidation Reaction of Ethanol. ACS Catal. 2015, $5(2), 1371-1380$.

(38) Mu, R. T.; Fu, Q. A.; Xu, H.; Zhang, H. I.; Huang, Y. Y.; Jiang, Z.; Zhang, S. O.; Tan, D. L.; Bao, X. H., Synergetic Effect of Surface and Subsurface Ni Species at Pt-Ni Bimetallic Catalysts for CO Oxidation. J. Am. Chem. Soc. 2011, 133 (6), 1978-1986.

(39) Park, K. W.; Choi, J. H.; Kwon, B. K.; Lee, S. A.; Sung, Y. E.; Ha, H. Y.; Hong, S. A.; Kim, H.; Wieckowski, A., Chemical and Electronic Effects of $\mathrm{Ni}$ in $\mathrm{Pt} / \mathrm{Ni}$ and $\mathrm{Pt} / \mathrm{Ru} / \mathrm{Ni}$ Alloy Nanoparticles in Methanol Electrooxidation. J. Phys. Chem. B 2002, 106 (8), 18691877 .

(40) Wang, L. L.; Zhang, D. F.; Guo, L., Phase-Segregated PtNi Chain-Like Nanohybrids with High Electrocatalytic Activity towards Methanol Oxidation Reaction. Nanoscale 2014, 6 (9), 4635-4641.

(41) Huttel, Y., Gas-Phase Synthesis of Nanoparticles. John Wiley \& Sons: Weinheim Germany, 2017.

(42) Ferrari, P.; Vanbuel, J.; Li, Y.; Liao, T.-W.; Janssens, E.; Lievens, P., The Double-Laser Ablation Source Approach. In Gas-
Phase Synthesis of Nanoparticles, Wiley-VCH Verlag GmbH \& Co. KGaA: Weinheim Germany, 2017; Chapter 4, pp 59-78.

(43) Liao, T.-W.; Yadav, A.; Hu, K.-J.; van der Tol, J.; Cosentino, S.; D'Acapito, F.; Palmer, R. E.; Lenardi, C.; Ferrando, R.; Grandjean, D.; Lievens, P., Unravelling the Nucleation Mechanism of Bimetallic Nanoparticles with CompositionTunable Core-Shell Arrangement. Nanoscale 2018, 10 (14), 66846694.

(44) Liao, T.-W.; Verbruggen, S. W.; Claes, N.; Yadav, A.; Grandjean, D.; Bals, S.; Lievens, P., TiOz Films Modified with Au Nanoclusters as Self-Cleaning Surfaces under Visible Light. Nanomaterials-Basel 2018, 8 (1).

(45) Vajda, S.; White, M. G., Catalysis Applications of SizeSelected Cluster Deposition. ACS Catal. 2015, 5 (12), 7152-7176.

(46) Sun, S. H.; Murray, C. B.; Weller, D.; Folks, L.; Moser, A., Monodisperse FePt Nanoparticles and Ferromagnetic FePt Nanocrystal Superlattices. Science 20oo, 287 (5460), 1989-1992.

(47) Cha, S. K.; Mun, J. H.; Chang, T.; Kim, S. Y.; Kim, J. Y.; Jin, H. M.; Lee, J. Y.; Shin, J.; Kim, K. H.; Kim, S. O., Au-Ag CoreShell Nanoparticle Array by Block Copolymer Lithography for Synergistic Broadband Plasmonic Properties. ACS Nano 2015, 9 (5), 5536-5543.

(48) Benkó, T.; Beck, A.; Frey, K.; Srankó, D. F.; Geszti, O.; Sáfrán, G.; Maróti, B.; Schay, Z., Bimetallic $\mathrm{Ag}-\mathrm{Au} / \mathrm{SiO}_{2}$ Catalysts: Formation, Structure and Synergistic Activity in Glucose Oxidation. Appl. Catal., A 2014, 479, 103-111.

(49) Haldar, K. K.; Kundu, S.; Patra, A., Core-Size-Dependent Catalytic Properties of Bimetallic Au/Ag Core-Shell Nanoparticles. ACS Appl. Mater. Interfaces 2014, 6 (24), 2194621953.

(50) Escalera-López, D.; Niu, Y.; Park, S. J.; Isaacs, M.; Wilson, K.; Palmer, R. E.; Rees, N. V., Hydrogen Evolution Enhancement of Ultra-Low Loading, Size-Selected Molybdenum Sulfide Nanoclusters by Sulfur Enrichment. Appl. Catal., B 2018, 235, 84-91.

(51) Duncan, M. A., Invited Review Article: Laser Vaporization Cluster Sources. Rev. Sci. Instrum. 2012, 83 (4).

(52) Geerts, L.; Cosentino, S.; Liao, T.-W.; Yadav, A.; Lin, P.C.; Zharinov, V. S.; Hu, K.-J.; Longo, A.; Pereira, L. M. C.; Grandjean, D.; Rongé, J.; Lievens, P.; Martens, J. A., Highly Active Oxygen Evolution Reaction Model Electrode Based on Supported Gas-Phase NiFe Clusters. Catal. Today 2019, 334, 59-67.

(53) Wang, Z.; Palmer, R., Intensity Calibration and Atomic Imaging of Size-Selected $\mathrm{Au}$ and Pd Clusters in AberrationCorrected HAADF-STEM. J. Phys.: Conf. Ser. 2012, 371 (1), o12o10.

(54) Choi, E.; Oh, S. J.; Choi, M., Charge-Transfer in NixPtı$\mathrm{x}$ Alloys Studied by X-Ray Photoelectron-Spectroscopy. Phys. Rev. $B$ 1991, 43 (8), 6360-6368.

(55) Li, Z.; Chen, H. Y. T.; Schouteden, K.; Picot, T.; Houben, K.; Liao, T.-W.; Van Haesendonck, C.; Pacchioni, G.; Lievens, P.; Janssens, E., Size-Dependent Penetration of Gold Nanoclusters through a Defect-Free, Nonporous $\mathrm{NaCl}$ Membrane. Nano Lett. 2016, 16 (5), 3063-3070.

(56) Wu, F. L.; Huang, D. L.; Yue, Y.; Liu, L., Template Growth of $\mathrm{Au}, \mathrm{Ni}$ and Ni-Au Nanoclusters on Hexagonal Boron Nitride/Rh(111): A Combined STM, TPD and AES Study. RSC Adv. 2017, 7 (70), 44169-44177.

(57) Netzer, F. P.; Madey, T. E., The Structure of Co on $\mathrm{Ni}(111)$. J. Chem. Phys. 1982, 76 (1), 710-715.

(58) Conrad, H.; Ertl, G.; Kuppers, J.; Latta, E. E., Adsorption of Co on Clean and Oxygen Covered Ni(111) Surfaces. Surf. Sci. 1976, 57 (2), 475-484.

(59) Li, Y.-D.; Liao, T.-W.; Wang, C.-X.; Chao, C.-S.; Hung, T.-C.; Ho, C.-Y.; Luo, M.-F.; Lai, Y.-L.; Hsu, Y.-J., The Decomposition of Methanol on Au-Pt Bimetallic Clusters Supported by a Thin Film of $\mathrm{Al}_{2} \mathrm{O}_{3} / \mathrm{NiAl}(100)$. RSC $A d v$. 2014, 4 (6o), 31602-31613. 
(6o) Hammer, B.; Morikawa, Y.; Norskov, J. K., CO Chemisorption at Metal Surfaces and Overlayers. Phys. Rev. Lett. 1996, 76 (12), 2141-2144.

(61) Löwdin, P. O., On the Non-Orthogonality Problem Connected with the Use of Atomic Wave Functions in the Theory of Molecules and Crystals. J. Chem. Phys. 1950, 18 (3), 365-375.

(62) Toda, T.; Igarashi, H.; Uchida, H.; Watanabe, M., Enhancement of the Electroreduction of Oxygen on Pt Alloys with $\mathrm{Fe}, \mathrm{Ni}$, and Co. J. Electrochem. Soc. 1999, 146 (10), 3750-3756.

(63) Kang, J.; Nam, S.; Oh, Y.; Choi, H.; Wi, S.; Lee, B.; Hwang, T.; Hong, S.; Park, B., Electronic Effect in Methanol Dehydrogenation on Pt Surfaces: Potential Control during Methanol Electrooxidation. J. Phys. Chem. Lett. 2013, 4 (17), 29312936.

(64) Greeley, J.; Mavrikakis, M., Competitive Paths for Methanol Decomposition on Pt(111). J. Am. Chem. Soc. 2004, 126 (12), 3910-3919.

(65) Ferrin, P.; Mavrikakis, M., Structure Sensitivity of Methanol Electrooxidation on Transition Metals. J. Am. Chem. Soc. 2009, 131 (40), 14381-14389.

(66) Ferrin, P.; Nilekar, A. U.; Greeley, J.; Mavrikakis, M.; Rossmeisl, J., Reactivity Descriptors for Direct Methanol Fuel Cell Anode Catalysts. Surf. Sci. 2008, 602 (21), 3424-3431.
(67) Vandamme, N.; Janssens, E.; Vanhoutte, F.; Lievens, P.; Van Haesendonck, C., Scanning Probe Microscopy Investigation of Gold Clusters Deposited on Atomically Flat Substrates. J. Phys.: Condens. Matter 2003, 15 (42), S2983-S2999.

(68) Fairley, N., CasaXPS Manual 2.3. 15: Introduction to XPS and AES. Casa Software, 2009.

(69) Singh-Miller, N. E.; Marzari, N., Surface Energies, Work functions, and Surface Relaxations of Low-Index Metallic Surfaces from First Principles. Phys. Rev. B 2009, 80 (23).

(7o) Hutter, J.; Iannuzzi, M.; Schiffmann, F.; VandeVondele, J., $\mathrm{CP}_{2} \mathrm{~K}$ : Atomistic Simulations of Condensed Matter Systems. Wiley Interdiscip. Rev.: Comput. Mol. Sci. 2014, 4 (1), 15-25.

(71) VandeVondele, J.; Krack, M.; Mohamed, F.; Parrinello, M.; Chassaing, T.; Hutter, J., QUICKSTEP: Fast and Accurate Density Functional Calculations Using a Mixed Gaussian and Plane Waves Approach. Comput. Phys. Commun. 2005, 167 (2), 103-128.

(72) Goedecker, S.; Teter, M.; Hutter, J., Separable DualSpace Gaussian Pseudopotentials. Phys. Rev. B 1996, 54 (3), 17031710.

(73) Hirshfeld, F. L., Bonded-Atom Fragments for Describing Molecular Charge-Densities. Theor. Chim. Acta 1977, $44(2), 129-138$. 
Insert Table of Contents artwork here

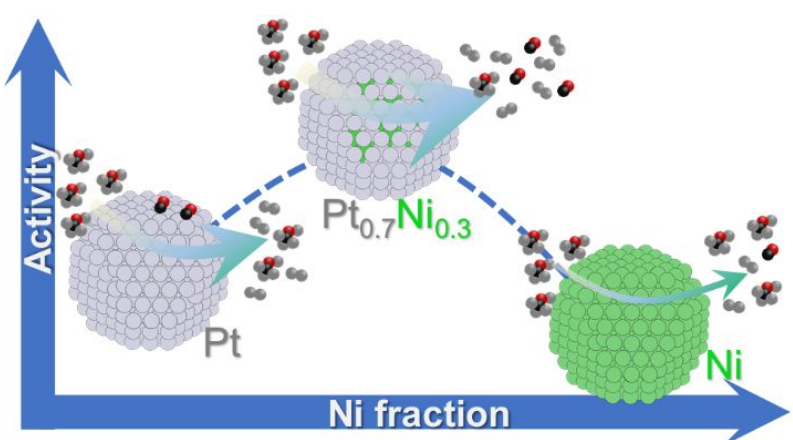

